\title{
Kesiapan Sekolah dalam Melaksanakan Pendidikan Inklusif untuk Anak Berkebutuhan Khusus di Sekolah Dasar
}

\author{
Dewi Rahmawati Hartadi, Dimas Arif Dewantoro, Ahsan Romadlon Junaidi \\ Universitas Negeri Malang \\ e-mail :dwrahmahrtd@gmail.com
}

\begin{abstract}
Abstrak : Malang belum memiliki peraturan yang jelas terhadap pendidikan inklusif, sehingga ada begitu banyak sekolah yang menafsirkannya sendiri. Tujuan dari penelitian ini adalah untuk menggambarkan kesiapan sekolah dalam mengimplementasikan pendidikan inklusif untuk siswa sekolah dasar di Lowokwaru, Malang. Menggunakan penelitian deskriptif kualitatif dan multisitus. Hasil dari penelitian ini adalah: (1) deskripsi implementasi inklusif, (2) deskripsi rencana inklusif, (3) deskripsi pembelajaran inklusif, dan (4) deskripsi evaluasi pendidikan inklusif di tingkat sekolah dasar di Lowokwaru, Malang. Kata Kunci : kesiapan, inklusif, dan regulasi.
\end{abstract}

\begin{abstract}
Malang has not had a clear regulation towards inclusive education, so that there are so many schools that interpret it by their own. The purpose of the study is to describe the readiness of school in implementing the inclusive education for elementary students at Lowokwaru, Malang. Using descriptive qualitative and multisitus research. The results from this study were: (1) the description of inclusive implementation, (2) the description of inclusive plan, (3) the description of inclusive learning, and (4) the description of inclusive education evaluation in elementary school level at Lowokwaru, Malang.

Keywords: readiness, inclusive, and regulation.
\end{abstract}

Pendiri bangsa menyadari akan pentingnya pendidikan, bahkan sebelum kemerdekaan Indonesia. Mereka memiliki keyakinan bahwa pendidikan bisa menjadi alat transformasi bangsa. Sebagai alat transformasi bangsa, pendidikan sering disebut dalam UUD 1945. Istilah pendidikan pada kenyataannya merupakan sistem yang terdiri dari beberapa komponen meliputi: peserta didik, pendidik, tujuan, alat, dan lingkungan. Semua komponen saling berkaitan, bergantung, dan menentukan satu sama lain (Arifin, 2015). Namun, komponen pendidikan masih belum memfasilitasi terutama untuk ABK. ABK juga ingin menikmati hak sebagai warga Negara untuk mendapatkan pendidikan. Pendidikan adalah hak dasar bagi setiap orang, tanpa melihat kelas sosial, ras, pilihan politik, kenyakinan, maupun perbedaan fisik dan mental (Kadir, 2015). Pendapat lain dikemukakan oleh Efendi (2018) yang menjelaskan bahwa dibutuhkan solusi cerdas supaya ABK dapat terpenuhi dan terlayai kebutuhan pendidikannya.

Memberikan hak pendidikan yang berkualitas untuk warga negara merupakan tantangan besar dan termasuk isu penting dalam dunia pendidikan. Ada beberapa Perjanjian Internasional yang memperkuat pernyataan tersebut yaitu tahun 1989 PBB yang telah mendeklarasikan hak untuk anak agar memperoleh pendidikan tanpa adanya diskriminasi atau Covention on the Rights of the Children, tahun 1993 yaitu hasil dari Resolusi Perserikatan Bangsa-Bangsa (PBB) No.48/96 mengenai kesempatan bagi orang berkelainan, dan Konferensi Internasional tahun 1990 di Jomtien, Thailand. Konfensi yang pernah berlangsung di Thailand mempersoalkan pendidikan untuk semua anak. Sejak dideklarasikan 'Pendidikan Untuk Seluruhnya' atau Education For All telah memantapkan komitmen Education For All dan mengeluarkan program kerja untuk pendidikan ABK yang diharapkan menjadi pegangan masyarakat dalam implementasi pendidikan untuk ABK (Pratiwi, 2015).

Sejarah perkembangan layanan pendidikan ABK terdapat dua model pendidikan, yaitu segregasi dan integrasi. Modal pertama yaitu pendidikan bentuk segregasi yang dikenal dengan Sekolah Luar Biasa (SLB), model kedua yaitu pendidikan berbentuk integrasi yang merupakan perpaduan antara pendidikan luar biasa dengan pendidikan regular atau kita kenal dengan istilah pendidikan inklusif dengan jenjang pendidikan yang meliputi Sekolah Dasar, Sekolah Menengah Pertama, Sekolah Menengah Atas, dan Perguruan Tinggi.

Terlepas dari dua model layanan pendidikan untuk ABK ada konsep mainstream yang sebenarnya merupakan sebuah sistem pendidikan yang menempatkan ABK di sekolah regular dengan ketentuan mengikuti kurikulum yang berlaku. Biasanya diselenggarakan untuk anak yang sedang sakit namun tidak berdampak pada kognitifnya seperti epilepsy, asma, dan hambatan sensori juga anak tunadaksa. Sejak munculnya konsep mainstream tahun 80-an, terdapat upaya kuat dalam melaksanakan pendidikan ABK secara terpadu di sekolah umum (Widyastono, 2007). Perkembangan pendidikan inklusif diawali dari Negara-negara Scandinavia (Denmark, Norwegia, Swedia). Adanya sistem pendidikan inklusif ditandai dengan mulai bergesernya model pendidikan untuk ABK yang semula dari segregatif menjadi pendidikan 
integratif. Perkembangan pendidikan inklusi memiliki keberagaman arti dalam dunia pendidikan.

Pendidikan di Indonesia mendapat jaminan yang telah diatur dalam UU No.20 Tahun 2003 yang menjelaskan lebih detail mengenai sistem pendidikan nasional. Salah satunya terdapat pada pasal 5 ayat 1 yang menyebutkan warga Negara mempunyai hak untuk memperoleh pendidikan bermutu. Kemudian ditegaskan lagi pada ayat 2 yaitu warga Negara yang memiliki kelainan baik dalam kondisi fisik, emosional dalam diri, mental dalam diri, intelektual yang terbentuk, dan sosial berhak memperoleh pendidikan khusus.

Berdasarkan perkembangan sejarah dunia, pemerintah Republik Indonesia pada tahun 2000 mengembangkan lagi sistem pendidikan inklusif. Sistem tersebut merupakan kelanjutan dari sistem pendidikan terpadu yang sebelumnya telah diterapkan di Indonesia tahun 1980, tetapi tidak berkembang dan dimulai lagi tahun 2000 dengan mengikuti perkembangan dunia pendidikan yang menggunakan sistem pendidikan inklusif.

Saat ini banyak lembaga pendidikan yang mengembangkan sistem pendidikan inklusif, mengingat cukup banyaknya jumlah ABK di Indonesia. Menurut Dirjen Dikdasmen yaitu Hamid Muhammad, membeberkan mengenai jumlah ABK di Indonesia tahun 2017 mencapai 1,6 juta anak. Sejumlah 1,6 juta ABK, baru $18 \%$ yang mendapatkan layanan pendidikan inklusi. Sejumlah 115 ribu ABK bersekolah di SLB, Pelaksana sekolah inklusi berjumlah 299 ribu. Bangsa Indonesia tentunya mendukung pengimplementasian dari sistem pendidikan inklusi yaitu dengan bukti sebagai berikut, pertama di Kabupaten Sidoarjo, Jawa Timur merupakan kota yang mendukung pengimplementasian pendidikan inklusif. Pemerintah Kabupaten Sidoarjo mengeluarkan Peraturan Bupati (Perbup) Sidoarjo No.6 Tahun 2011, tentang pendidikan khusus dan pendidikan layanan khusus, termasuk pedoman mengenai pendidikan inklusif. Pemerintah Sidoarjo mencanangkan visi jangka panjang yaitu menjadikan Sidoarjo sebagai Kabupaten penyelenggara pendidikan inklusif. Hal tersebut dibuktikan dengan dialokasikannya sekitar $25 \%$ dari total anggaran daerah ke dalam pendanaan untuk pendidikan di Sidoarjo tahun 2013 lalu. Bukti kedua, data diperoleh dari Dinas Pendidikan Kota Surabaya tahun 2015 telah menunjuk total 262 sekolah penyelenggara pendidikan inklusif yang terdiri dari 168 sekolah dasar, 90 sekolah menengah pertama, 2 sekolah menengah atas, dan 2 sekolah menengah kejuruan, tersebar di seluruh Surabaya. Aspek yang mempengaruhi keberhasilan implementasi pendidikan inklusif di Surabaya yaitu kebijakan ketersediaan sumber daya manusia yang memadai, disposisi, dan struktur birokrasi.

Praktisi yang berpartisipas dan mengamati implementasi secara langsung menganggap pendidikan inklusi di Indonesia hanya kebijakan yang semu. Kenyataan yang ditemui di lapangan, bahwa pendidikan inklusif di Indonesia belum merangkul keberagaman siswa, sehingga timbullah segmentasi lembaga pendidikan yang berdasar perbedaan agama, etnis, bahkan kemampuan fisik dan mental yang dimiliki siswa. Hal tersebut membuat opini bahwa pendidikan inklusi belum siap dalam proses implementasi.

Berdasarkan hal tersebut, maka diperlukan penelitian lanjutan khususnya mengenai kesiapan sekolah dalam implementasi pendidikan inklusif bagi ABK di Sekolah Dasar Kecamatan Lowokwaru, Kota Malang. Peneliti akan melihat langsung pengimplementasian pendidikan inklusif di beberapa Sekolah Dasar Kecamatan Lowokwaru.

\section{METODE}

Penelitian ini menggunakan pendekatan kualitatif. Penelitian kualitatif yaitu metode untuk mengeksplorasi dan memahami makna oleh sejumlah individu atau kelompok yang berasal dari masalah sosial atau kemanusiaan (Creswell, 2017). Penelitian menghasilkan data deskriptifberupa kata-kata tertulis atau lisan dari orang-orang dan perilaku yang diamati.

Penerapan metode kualitatif deskriptif semua yang dikumpulkan bisa jadi kunci yang telah diteliti (Moleong, 2014). Sedangkan rancangan penelitian ini adalah multi situs. Bogdan dan Biklen, mengembangkan teori yang diangkat dari beberapa latar penelitian yang serupa, sehingga dapat dihasilkan teori yang bisa ditransfer ke situasi yang lebih luas dan lebih umum cakupan yang ditemukan. Peneliti berupaya mengamati dan menganalisa kesiapan sekolah dalam implementasi pendidikan inklusif di Kecamatan Lowokwaru, Kota Malang. Hal ini dimaksudkan untuk mengetahui lebih dalam lagi pengimplementasian dalam sistem pendidikan inklusif.

\section{HASIL DAN PEMBAHASAN}

\section{Hasil}

Berdasarkan paparan data yang telah dikemukakan di atas, maka diperoleh hasil temuan penelitian yang ditunjukkan pada tabel 1, 2, dan 3 . 
Tabel 1: Temuan Penelitian di Sekolah A

\begin{tabular}{|c|c|c|}
\hline No & Aspek Temuan & Uraian \\
\hline 1 & Peserta Didik & $\begin{array}{l}\text { a) Penerimaan ABK karena sistem zonasi dan juga berdasarkan kemampuan sekolah } \\
\text { b) Sekolah bekerjasama dengan pihak psikologi untuk melakukan identifikasi dan } \\
\text { asesmen } \\
\text { c) Identifikasi dan asesmen menjadi dasar dalam menentukan program layanan } \\
\text { kompensatori serta akademik }\end{array}$ \\
\hline 2 & $\begin{array}{l}\text { Tenaga Pendidik dan } \\
\text { Kependidikan }\end{array}$ & $\begin{array}{l}\text { a) Guru regular menangani peserta didik } A B K \\
\text { b) GPK Kecamatan setiap satu bulan sekali rutin mengadakan pertemuan } \\
\text { antar guru yang menangani } A B K\end{array}$ \\
\hline 3 & Kurikulum & a) Tidak ada kurikulum khusus \\
\hline 4 & Pengelolaan Kelas & a) Disamakan dengan kelas regular \\
\hline 5 & Kegiatan Pembelajaran & $\begin{array}{l}\text { a) Sama seperti kelas regular lainnya } \\
\text { b) Ada shadow yang membantu ketika ABK kesulitan dalam pembelajaran }\end{array}$ \\
\hline 6 & $\begin{array}{l}\text { Sistem Kenaikan Kelas dan } \\
\text { Laporan Hasil Belajar }\end{array}$ & $\begin{array}{l}\text { a) Disamakan dengan kelas regular, namun ada penurunan Kriteria } \\
\text { Ketuntasan Minimal (KKM) } \\
\text { b) Hanya saja ijasah dibuat khusus untuk ABK }\end{array}$ \\
\hline 7 & $\begin{array}{l}\text { Faktor Pendukung dan } \\
\text { Penghambat }\end{array}$ & $\begin{array}{l}\text { a) Sekolah belum memiliki GPK, sementara dibantu oleh guru regular } \\
\text { b) Media pembelajaran untuk ABK kurang memadai }\end{array}$ \\
\hline
\end{tabular}

Tabel 2: Temuan Penelitian di Sekolah B

\begin{tabular}{|c|c|c|}
\hline No & Aspek Temuan & Uraian \\
\hline \multirow[t]{5}{*}{1} & Peserta Didik & a) Setiap tahun ajaran baru, sekolah hanya menerima $2 \mathrm{ABK}$ \\
\hline & & b) Penerimaan ABK berdasarkan kemampuan sekolah \\
\hline & & c) Melakukan asesmen kepada calon peserta didik ABK \\
\hline & & d) Identifikasi dan asesmen menjadi dasar dalam menentukan program \\
\hline & & layanan kompensatori serta akademik \\
\hline \multirow[t]{3}{*}{2} & Tenaga Pendidik dan Kependidikan & a) Kualifikasi akademik GPK adalah S1 Psikologi dan mahasiswa PLB \\
\hline & & b) GPK Kecamatan setiap satu bulan sekali rutin mengadakan pertemuan \\
\hline & & antar guru yang menangani ABK \\
\hline \multirow[t]{2}{*}{3} & Kurikulum & a) Menggunakan kurikulum modifikasi \\
\hline & & b) Layanan kekhususan terdiri dari bina diri, fokus belajar, dan berani. \\
\hline 4 & Pengelolaan Kelas & a) Menggunakan model kelas pull out, cluster, dan ruang sumber. \\
\hline \multirow[t]{2}{*}{5} & Kegiatan Pembelajaran & a) Ada sebagian $\mathrm{ABK}$ yang masih didampingi oleh shadow \\
\hline & & b) Evaluasi pembelajaran di kelas regular diturunkan KKM untuk ABK \\
\hline \multirow[t]{2}{*}{6} & Sistem Kenaikan Kelas & a) ABK dinaikkan semua, tidak ada yang tinggal kelas \\
\hline & Laporan Hasil Belajar & \\
\hline 7 & Faktor Pendukung dan Penghambat & a) Belum ada kejelasan regulasi mengenai pendidikan inklusif \\
\hline
\end{tabular}

\section{Pembahasan}

Pengimplementasian Sistem Pendidikan Inklusif Di Kecamatan Lowokwaru

Upaya dalam mengenalkan dan mengimplementasi sistem pendidikan inklusif di Indonesia sudah dimulai sejak tahun 1980an. Program pendidikan inklusif semakin kokoh dengan adanya dukunngan dari peraturan pemerintah pusat maupun pemerintah daerah (Efendi, 2018). Malang merupakan salah satu kota inklusif. Ada tiga sekolah yang akan menjadi subjek penelitian. Sekolah A dengan moto yang selalu diunggulkan menjadikan salah satu faktor berdirinya sekolah inklusif. Sekolah A memiliki prespektif sendiri mengenai pengimplementasian pendidikan inklusif dengan harapan semoga itu yang terbaik untuk ABK. Selain itu, Sekolah A juga terkenal dengan sekolah yang menampung segala jenis ABK. 
Tabel 3: Temuan Penelitian di Sekolah C

\begin{tabular}{|c|c|c|}
\hline No & Aspek Temuan & Uraian \\
\hline \multirow[t]{5}{*}{1} & Peserta Didik & 1) Setiap tahun ajaran baru, sekolah hanya menerima $4 \mathrm{ABK}$ \\
\hline & & 2) Penerimaan ABK berdasarkan kemampuan sekolah \\
\hline & & 3) Melakukan asesmen kepada calon peserta didik ABK \\
\hline & & 4) Identifikasi dan asesmen menjadi dasar dalam menentukan program layanan \\
\hline & & kompensatori serta akademik \\
\hline \multirow[t]{3}{*}{2} & Tenaga Pendidik & 1) Kualifikasi akademik GPK adalah lulusan dari S1 PLB, S1 Psikologi, dan \\
\hline & Kependidikan & SMP/SMA \\
\hline & & 2) GPK Kecamatan setiap satu bulan sekali rutin mengadakan pertemuan antar \\
\hline \multirow[t]{3}{*}{3} & Kurikulum & 1) Ada modifikasi kurikulum untuk ABK \\
\hline & & 2) Ada beberapa ABK yang menggunakan Program Pembelajaran Individu (PPI \\
\hline & & PPI dbuat oleh GPK dengan berkonsultasi guru regular \\
\hline \multirow[t]{2}{*}{4} & Pengelolaan Kelas & 1) Model kelas ABK pullout dan cluster \\
\hline & & 2) Ada ruang sumber \\
\hline \multirow[t]{2}{*}{5} & Kegiatan Pembelajaran & 1) Pembelajaran dilakukan seperti kelas regular lainnya \\
\hline & & 2) Ada GPK untuk masing-masing ABK \\
\hline \multirow[t]{3}{*}{6} & Sistem Kenaikan Kelas dan & 1) ABK tidak ada yang tinggal kelas \\
\hline & Laporan Hasil Belajar & 2) Ujian Sekolah ditentukan berdasarkan kemampuan $A B K$ \\
\hline & & 3) Pembagian rapot sama seperti kelas regular \\
\hline 7 & $\begin{array}{l}\text { Faktor Pendukung dan } \\
\text { Penghambat }\end{array}$ & $\begin{array}{l}\text { 1) Belum maksimal pemerataan tenaga didik lulusan PLB agar keprofesionalan } \\
\text { terjaga }\end{array}$ \\
\hline
\end{tabular}

Namun, masih terbatas karena harus menyesuaikan dengan rombel yang tersedia setiap tahunnya hanya menerima 4 ABK saja. Hal ini sangat disayangkan, dengan nama yang sudah dikenal oleh sebagian besar masyarakat Malang seharunya menjadikan sekolah menambahkan kuota untuk ABK. Di Sekolah A juga masih masih minim tenaga didik lulusan dari Pendidikan Luar Biasa (PLB). Sekolah A menerima segala macam kelulusan untuk menjadi GPK, ada yang berasal dari SMP, SMA, jurusan psikologi, jurusan pendidikan, dsb. Hal tersebut akan menurunkan kualitas atau standar yang sudah ditetapkan pedoman pendidikan inklusif. Meskipun begitu, sekolah sedang berupaya memberikan pelayanan terbaik dan selalu upgrade informasi terkini mengenai pendidikan inklusif.

Kedua, Sekolah B yang ditunjuk sebagai sekolah percontohan bagi sekolah dasar yang mengimplentasikan pendidikan inklusif. Dalam pengimplementasiannya Sekolah B menekankan pada keterpaduan penuh, menghilangkan labelisasi anak (normal dan menekankan pada keterpaduan penuh, menghilangkan labelisasi anak (normal dan tidak normal) dengan prinsip "Education for all". Namun, sekolah belum sepenuhnya mengimplementasikan pendidikan inklusif sesuai pedoman inklusi di Indonesia. Sebagai bukti penguat, sekolah belum memiliki perangkat pembelajaran seperti PPI dan
RPP khusus. Meskipun tujuan dari sekolah adalah menyetarakan dengan anak regular. Akan tetapi, sekolah masih memiliki ABK yang membutuhkan modifikasi dalam pembelajaran. Di awal PPDB Sekolah B juga masih memilih calon peserta didik yang akan diterima. Dari beberapa ABK yang mendaftar hanya 2-3 ABK saja yang diterima, itu pun dengan syarat dan ketentuan yang berlaku dikalangan guru. Sekolah B belum memiliki akses dan sarana prasarana yang memadai untuk menerima segala jenis ketunaan. Dan juga sekolah B masih minim lulusan dari PLB yang seharusnya ada sebagai GPK untuk menunjang kemajuan sistem pendidikan inklusif khususnya di Malang.

Ketiga, Sekolah C sudah ada sejak tahun 80an. Pada saat itu sekolah hanya mengenal penerimaan untuk siswa regular saja. Seiring berjalannya waktu dan semakin berkembangnya dunia pendidikan, Dinas Pendidikan Kota Malang mulai menerapkan sistem zonasi sesuai Permendikbud Nomor 14 tahun 2018 yang menerapkan sistem zonasi. Dengan berlakunya regulasi tentang zonasi penerimaan peserta didik baru (PPDB), maka mulai saat itulah pendidikan inklusif di sekolah C diimplikasikan. Ketika PPDB sekolah diharuskan menerima peserta didik yang tinggal disekitar sekolah tanpa pengecualian termasuk di dalamnya ada ABK. Namun, sekolah masih membatasi pendaftaran untuk ABK. Hal ini disebabkan karena 
sekolah belum memiliki GPK untuk menunjang pembelajaran ABK. Padahal keberadaan GPK sangat penting jika sekolah menerapkan pendidikan inklusif. Di Sekolah C ABK yang bersekolah diberlakukan sama seperti siswa regular, hal ini dikarenakan kemampuan siswa dianggap sama seperti siswa regular. Kenyataan yang terjadi, masih ditemui kesulitan dalam proses pembelajaran dan tidak adanya pendampingan pada salah satu ABK. Pengimplementasian sistem pendidikan inklusif dari ketiga sekolah pelaksanaan pendidikan inklusif dipengaruhi oleh banyak faktor, antara lain: faktor budaya, politik, dan sumber daya manusia (Kwon, 2005).

\section{Perencanaan Kebutuhan Belajar Pendidikan Inklusif di Kecamatan Lowokwaru}

Merencanakan sebuah strategi untuk mempromosikan sekolah regular yang akan dijadikan sekolah inklusif, maka sekolah harus bertanggungjawab atas kebutuhan anak dan warga sekolah (Yusuf, Choiri \& Gunarhadi: 2018). Sekolah A merencanakan penyediaan pembelajaran untuk ABK dilakukan di awal tahun ajaran baru. GPK bersama tim penyusun rencana belajar sudah membuat program pembelajaran individu berupa pemetaan target pembelajaran. Setiap ABK dibuatkan PPI jangka panjang dan jangka pendek. Untuk PPI jangka panjang kurun waktunya adalah 1 tahun, inti dari PPI tersebut adalah penyederhanaan KD. Sedangkan untuk PPI jangka pendek kurun waktunya adalah 3 bulan. Jadi turunan KD dalam PPI jangka panjang bisa dibuat fleksibel pada PPI jangka pendek yang nantinya berguna untuk mengetahui kemampuan anak dan mengikuti perkembangan anak. Sekolah B untuk merencanakan kebutuhan belajar di awal sebelum memasuki tahun ajaran baru. Sekolah mengadakan trial class yang berguna untuk penempatan kelas anak. penempatan dibagi menjadi dua yaitu, kelas regular dan kelas inklusif. Sementara ini di sekolah menampung 8 ABK, 6 diantaranya mengikuti pembelajaran regular dan 2 lagi mengikuti kelas inklusif. Ketiga, Sekolah $\mathrm{C}$ dalam perencanaan kebutuhan belajar untuk ABK tidak banyak yang dilakukan. Kebutuhan disesuaikan dengan anak regular. Hal ini dikarenakan ABK yang ada di sekolah kemampuannya setara dengan anak regular, hanya saja sedikit mengalami keterlambatan dalam belajar. Untuk mengantisipasi ketika mengalami keterlambatan sekolah bekerjasama dengan sekolah untuk menggunakan jasa shadow. Adapun suplemen Penyelenggaraan Pendidikan Inklusif menurut Pedoman Inklusif (2011), yaitu:

1) Model Program Pembelajaran Individual

2) Model Modifikasi Bahan Ajar

3) Model Rencana Program Pembelajran

4) Model Media Pembelajaran

5) Model Program Tahunan

6) Model Laporan Hasil Belajar (Raport)
Pelaksanaan Pembelajaran Pendidikan Inklusif Di Kecamatan Lowokwaru

Melaksanakan pembelajaran inklusif masingmasing sekolah memiliki ketetapan sendiri bergantung kebutuhan ABK. Singh\&Agarwal (2015) mengatakan pendidikan inklusif didasarkan pada prinsip bahwa sekolah harus menyediakan pembelajaran untuk semua anak tanpa memandang perbedaan yang dirasakan, cacat fisik atau keadaan sosial, budaya, dan perbedaan lainnya. Sekolah A pembelajaran yang dikembangkan berdasarkan children multiple intelligence development dengan PAKEMI Learning. Pengembangan pembelajaran tahunan menganut pada aspek perkembangan pendidikan nilai dan moral agama, sosial emosi, bahasa, kognitif, fisik motorik, seni, dan keterampilan hidup. Program pembelajaran juga didukung dengan kelas kecil maksimal 30 peserta didik setiap kelasnya dengan team teaching atau dibimbing dua orang guru tiap kelasnya dan professional resource. Untuk ABK sekolah memiliki 2 GPK yaitu, GPK sekolah dan GPK kolaborasi. Ada RPP khusus dan juga PPI untuk menunjang pembelajaran ABK. Di dalam kelas ABK ikut belajar bersama dengan anak regular lainnya, hanya saja materi yang digunakan menyesuaikan kemampuan masing-masing individu.

Sekolah B dalam melaksanakan pembelajaran pendidikan inklusif sebagian ABK sudah ada yang diikutkan kelas regular. Setelah dilihat kemampuan anak. seperti yang dilakukan diawal pada saat pendaftaran. Sekolah memberikan layanan trial class. Kelas tersebut untuk uji kemampuan ABK. Kedepannya akan ditempatkan di kelas regular atau kelas inklusif. Dalam pembelajaran inklusif sekolah mengimplementasikan metode, sumber/media belajar, dan bahan latihan yang sesuai dengan kemampuan awal dan karakteristik siswa, serta sesuai dengan tujuan pembelajaran. Namun, di SDN Percobaan 1 belum dapat terlaksana sepenuhnya. Sebagian ABK mengikuti kelas regular. Hanya ada 2 ABK yang dimodifikasi pembelajarannya.

Sekolah C dalam pelaksanaan pendidikan inklusif menerapkan sistem kelas inklusif penuh. Kelas inklusif penuh merupakan kelas untuk anak berkebutuhan khusus yang ikut belajar bersama dengan anak normal lainnya sepanjang hari di kelas dengan menggunakan kurikulum yang sama. Hal ini karena ABK yang bersekolah di Sekolah $\mathrm{C}$ masih termasuk kategori ABK yang bisa diikutkan belajar dengan anak regular. Untuk hasil pembelajaran sama seperti anak regular lainnya. Tentunya aka nada keterangan bahwa itu adalah rapor untuk ABK.

Evaluasi dari Pengimplementasian Sistem Pendidikan Inklusif Di Kecamatan Lowokwaru

Sekolah A mengadakan pertemuan antar GPK sekolah dengan GPK kolaborasi setiap hari 
sabtu. Dalam pertemuan biasanya para GPK bercerita dan berbagi pengalaman selama hari kerja (seninjumat). Seringnya dalam pertemuan tersebut kami menyamakan prespektif mengenai pendidikan inklusif. Kegiatan yang paling ditunggu adalah belajar komputer bersama. Seiring berkembangnya jaman kami ingin semua tenaga didik kami melek akan teknologi. Tidak peduli mereka lulusan SMP, SMA, atau S1 disini semua GPK belajar bersama dan dipandu langsung oleh koordinator inklusif.

Pengimplementasian pendidikan inklusif di Sekolah B perlu evaluasi dalam hal perencanaan kebutuhan belajar. Perencanaan tersebut meliputi perangkat pembelajaran seperti RPP atau PPI untuk keberlangsungan proses belajar mengajar ABK. Meskipun tujuan sekolah adalah menyetarakan dengan anak regular tidak dapat dipungkiri ada sebagian ABK yang masih membutuhkan modifikasi pembelajaran.

Sekolah C meskipun kekurangan tenaga profesional yang menunjang terselenggaranya pendidikan inklusif, sekolah mengupayakan yang terbaik untuk peserta didik. Selain itu, bentuk kepedulian guru-guru yaitu dengan mencarikan informasi dari sekolah sebelah (SDN Tunjungsekar 4) yang juga termasuk sekolah inklusif. Sehingga sekolah masih bergantung informasi. Di Kecamatan Lowokwaru ada sebuah paguyuban antar GPK. Di paguyuban ini para GPK dapat saling bertukar pendapat dan pengalaman. Saat ini dengan adanya koordinasi inklusif di sekolah sangat membantu menangani pembelajaran inklusif

\section{KESIMPULAN DAN SARAN}

\section{Kesimpulan}

Ketiga sekolah dalam mengimplementasikan pendidikan inklusif belum siap mengimplementasikan karena beberapa faktor. Faktor ketidaksiapan yang ada di sekolah A adalah tidak adanya tenaga didik yang berasal dari lulusan S1 PLB. Sekolah B masih belum siap dalam hal pembelajaran. Dan sekolah $\mathrm{C}$ belum siap dengan tenaga didik dan sarana prasarana. Perencanaan yang dilakukan masing-masing sekolah bergantung kebutuhan belajar ABK. Ada sekolah yang fokus pada RPP dan PPI, ada sekolah yang fokus persiapan, dan ada juga sekolah yang hanya fokus pada pendampingan.

\section{Saran}

Adanya pendidikan inklusif yang sedang berlangsung di beberapa sekolah dasar kecamatan Lowokwaru saat ini menjadikan seluruh warga sekolah menerima keberadaan ABK. Dalam pengimplementasian, perencanaan, pembelajaran, dan evaluasi perlu pertimbangan yang lebih matang lagi agar sekolah lebih siap lagi dalam pelaksanaan pendidikan inklusif.

\section{DAFTAR RUJUKAN}

Arifin, H. M. (2015). Faktor-faktor determinan dalam pendidikan, 8(2), 1-17.

Efendi,M., \& Malang, U.N.(2018). The Implementation of Inclusive Education in Indonesia for Children with Special Needs: Expectation and Reality, 2(1), 142-147.

Inklusif, P. P. (2011). Pedoman Umum Pedoman Umum Penyelenggaraan Pendidikan Inklusif, (70).

Kadir, A. (2015). Penyelenggaraan Sekolah Inklusi Di Indonesia Abd. Kadir (Dosen PAI FTK UIN Sunan Ampel Surabaya). Pendidikan Agama Islam, 03, 1-22.

Miles, B. Matthew. Huberman, A. Saldana, J. (2014). Qualitative Data Analysis: A Methods Sourcebook. Edition 3. Arizona State University: Sage

Moleong, L. (2014). Metodologi Penelitian Kualitatif. Bandung.

Nations, U. (1994). The Salamanca Statement Framework, (June), 7-10.

Pratiwi, J. C. (2015). Sekolah Inklusi Untuk Anak Berkebutuhan Khusus: Tanggapan Terhadap Tantangan Kedepannya, (November), 237-242.

Profile, S. E. E. (2015). Problems and prospects of inclusive education in india, (March).

Saat, S. 2015. Faktor-Faktor Determinan Dalam Pendidikan. Jurnal Al-Ta'dib, 2(8).

Undang - Undang Republik Indonesia Nomor 4 Tahun 1997 tentang penyandang cacat. . TIM KPAI.

Undang-Undang Republik Indonesia Nomor 20 Tahun 2003 tentang Sistem Pendidikan Nasional.

Widyastono, H. (2007). Penyelenggaraan Pendidikan Inklusi bagi Anak Berkelainan. Jurnal Pendidikan dan Kebudayaan, 13(65), 314-324.

$\begin{array}{lrr}\text { Yusuf, M., \& } & \text { Choiri, } \\ \text { S. (2018). The Effectiveness } & \text { of } \\ \text { Inclusive Education and } & \text { Child } \\ \text { Protection Training on Understanding } & \\ \text { Inclusive Education Subject Matter, } & 2(1), \\ \text { 1-6. } & \end{array}$

